\title{
Power Quality and Voltage Sag Indices in Electrical Power Systems
}

\author{
Alexis Polycarpou \\ Frederick University \\ Cyprus
}

\section{Introduction}

In modern electrical power systems, electricity is produced at generating stations, transmitted through a high voltage network, and finally distributed to consumers. Due to the rapid increase in power demand, electric power systems have developed extensively during the 20th century, resulting in today's power industry probably being the largest and most complex industry in the world. Electricity is one of the key elements of any economy, industrialized society or country. A modern power system should provide reliable and uninterrupted services to its customers at a rated voltage and frequency within constrained variation limits. If the supply quality suffers a reduction and is outside those constrained limits, sensitive equipment might trip, and any motors connected on the system might stall. The electrical system should not only be able to provide cheap, safe and secure energy to the consumer, but also to compensate for the continually changing load demand. During that process the quality of power could be distorted by faults on the system, or by the switching of heavy loads within the customers facilities. In the early days of power systems, distortion did not impose severe problems towards end-users or utilities. Engineers first raised the issue in the late 1980s when they discovered that the majority of total equipment interruptions were due to power quality disturbances. Highly interconnected transmission and distribution lines have highlighted the previously small issues in power quality due to the wide propagation of power quality disturbances in the system. The reliability of power systems has improved due to the growth of interconnections between utilities.

In the modern industrial world, many electronic and electrical control devices are part of automated processes in order to increase energy efficiency and productivity. However, these control devices are characterized by extreme sensitivity in power quality variations, which has led to growing concern over the quality of the power supplied to the customer.

According to the IEEE defined standard (IEEE Std. 1100, 1999), power quality is "The concept of powering and grounding electronic equipment in a manner suitable to the operation of that equipment and compatible with the premise wiring system and other connected equipment". Some authors use the term 'voltage quality' and others use 'quality of supply' to refer to the same issue of power quality. Others use the term 'clean power' to refer to an intolerable disturbance free supply. Power quality is defined and documented in established standards as reliability, steady state voltage controls and harmonics. Voltage sag is defined as a short reduction in voltage magnitude for a duration of time, and is 
considered to be the most common power quality issue. The economic impact of power quality on a utility is of great importance. Living in a world where making money is the major objective of electricity companies, quality is often overlooked. Thus a need for specific, easy to assess and well-defined performance criteria for use worldwide encouraged the definition and establishment of Power Quality indices.

In the first section of this chapter Power quality disturbances, such as Voltage sag, Interruption, transient overvoltage, swell, Harmonic issues and voltage imbalance, are Introduced. Statistical voltage sag Indices used for characterization and assessment of power quality are then presented. These indices classify within the following categories: Single event, Site indices and System indices. Furthermore the development and verification of Mathematical voltage sag indices is presented, applicable for power quality improvement through optimization techniques. The impact on the voltage profile of heavy induction motor load switching is predicted, and the possibility to mitigate potential power quality violations before they occur is created. Finally the chapter conclusions are presented, highlighting the importance of the statistical indices and how the mathematical indices could further enhance the power quality of an electric power system.

\section{Power quality disturbances}

There is a wide variety of power quality disturbances which affect the performance of customer equipment. The most common of these are briefly described in this section of the chapter.

\subsection{Voltage sags}

Voltage Sag is defined as a short reduction in voltage magnitude for a duration of time, and is the most important and commonly occurring power quality issue. The definitions to characterise voltage sag in terms of duration and magnitude vary according to the authority. According to the IEEE defined standard (IEEE Std. 1159, 1995), voltage sag is defined as a decrease of rms voltage from 0.1 to 0.9 per unit (pu), for a duration of 0.5 cycle to 1 minute. Voltage sag is caused by faults on the system, transformer energizing, or heavy load switching.

\subsection{Interruptions}

Interruption is defined as a 0.9 pu reduction in voltage magnitude for a period less than one minute. An interruption is characterized by the duration as the magnitude is more or less constant. An interruption might follow a voltage sag if the sag is caused by a fault on the source system. During the time required for the protection system to operate, the system sees the effect of the fault as a sag. Following circuit breaker operation, the system gets isolated and interruption occurs. As the Auto-reclosure scheme operates, introduced delay can cause a momentary interruption.

\subsection{Transient overvoltages, swells}

Overvoltage is an increase of Root Mean Square (RMS) voltage magnitude for longer than one minute. Typically the voltage magnitude is 1-1.2 pu and is caused by switching off a large load from the system, energizing a capacitor bank, poor tap settings on the transformer and inadequate voltage regulation. Overvoltages can cause equipment damage 
and failure. Overvoltages with duration of 0.5 cycle to $1 \mathrm{~min}$ are called voltage swells. A swell is typically of a magnitude between 1.1 and $1.8 \mathrm{pu}$ and is usually associated with single line to ground faults where voltages of non-faulted phases rise.

\subsection{Harmonic issues}

The increasing application of power electronic devices like adjustable speed drives, uninterruptible power supplies and inverters, raises increasing concerns about harmonic distortion in the power system. These devices can not only cause harmonics in the system but are also very sensitive to voltage-distorted signals. The presence of harmonics in the system could also cause several unwanted effects in the system including excessive transformer heating or overloading and failure of power factor correcting capacitors.

The maximum total harmonic distortion which is acceptable on the utility system is $5.0 \%$ at $2.3-69 \mathrm{kV}, 2.5 \%$ at $69-138 \mathrm{kV}$ and $1.5 \%$ at higher than $138 \mathrm{kV}$ voltage levels (IEEE Std. 1250, 1995).

\subsection{Voltage imbalance}

This type of power quality disturbance is caused by unequal distribution of loads amongst the three phases. At three-phase distribution level, unsymmetrical loads at industrial units and untransposed lines can result in voltage imbalance. Voltage imbalance is of extreme importance for three-phase equipment such as transformers, motors and rectifiers, for which it results in overheating due to a high negative sequence current flowing into the equipment. The asymmetry can also have an adverse effect on the performance of converters, as it results in the production of harmonic.

\section{Voltage sag statistical indices}

For many years, electricity companies have used sustained interruption indices as indicators describing the quality and reliability of the services they provide. In order to compare power quality in different networks, regulators need to have common, standardised quality indices. The number of these indices should be kept at a minimum, easy to assess, and be representative of the disturbance they characterise. This section briefly discusses various voltage sag indices proposed by electrical association organisations and indices suggested by recent researchers. These indices are used to characterise any voltage sag, according to the individual index point of view. The procedure to evaluate the quality of supply, reference to non-rectangular events and equipment compatibility issues are also discussed.

\subsection{Types of indices}

Any available voltage sag index can be classified within the following three categories (Bollen, 2000).

a. Single-event index: a parameter indicating the severity of a voltage or current event, or otherwise describing the event. Each type of event has a specific single-event index.

b. Single-site index: a parameter indicating the voltage or current quality or a certain aspect of voltage or current quality at a specific site.

c. System index: a parameter indicating the voltage or current quality or a certain aspect of voltage or current quality for a whole or part of a power system. 
The procedure to evaluate the power systems performance regarding voltage sag is as follows (Bollen, 2000).

a. Step 1- Obtain sampled voltages with a certain sampling rate and resolution.

b. Step 2-Calculate event characteristics as a function of time, from the sampled voltages.

c. Step 3-Calculate single event indices from the event characteristics.

d. Step 4-Calculate site indices from the single-event indices of all events measured during a certain period of time.

e. Step 5-Calculate system indices from the site indices for all sites within a certain power system.

Each step mentioned above is discussed in the following parts of this chapter, with more detail given on the steps involving the various index types. Step 1 is not discussed at all since it simply represents the procedure to obtain voltage samples for every event with a certain sampling rate and resolution.

\subsection{Event characteristics}

From the sampled voltages, the characteristic voltage magnitude as a function of time can be obtained. Methods to accomplish this, using three phase measurements are (Bollen \& Styvaktakis, 2000):

a. Method of Symmetrical components: From the voltage magnitude and phase angle, a sag type is obtained along with the characteristic voltage, and Zero sequence voltage. The characteristic magnitude (the absolute value of the characteristic complex voltage) can be used to characterize three-phase unbalanced dips without loss of essential information. Using the characteristic magnitude and duration for three-phase unbalanced dips, corresponds to the existing classification (through magnitude and duration) for single-phase equipment.

b. Method based on six rms voltages: The procedure used in this method is to calculate the zero sequence component of the voltage and remove it from the phase voltages. The new phase to phase voltages can then be calculated. From the phase to phase voltages and the three phase voltages, the rms values can be calculated. The characteristic magnitude would then be the lowest of the six rms voltages.

\subsection{Single event indices}

From the event characteristics as a function of time, a number of indices are determined that describe the event. For some applications the phase angle at which the sag begins is important and called 'point on wave of dip initiation'. Using the concept of point on wave the exact beginning of the voltage dip can be identified (Bollen, 2001). In addition the point on wave of voltage recovery allows precise calculation of the sag duration. The maximum phase shift can be obtained from the voltage characteristic versus time and can be used for accurate phase-angle jump calculation. The maximum slew rate, and zero sequence voltage are mentioned as potential single event indices. The Canadian electrical association uses two approved quality indices: RMS Overvoltage (RMSO) and Undervoltage (RMSU) (Bergeron,R., 1998). The indices are assessed over intervals equal to the time needed for equipment to reach its steady-state temperature. The heating time constant, which varies with the size and nature of the equipment, has been divided into three classes:

a. Highly sensitive electronic systems with a heating time constant of less than $600 \mathrm{~ms}$.

b. Varistors and power electronics with a 2-min heating time constant. 
c. Electrical apparatus with a heating time constant exceeding $24 \mathrm{~min}$.

Canadian utilities have retained 2-min heating time constant to assess the factor related to overvoltages and undervoltages. This factor is measured over $10 \mathrm{~min}$ intervals $(5 \times 2 \mathrm{~min})$.

The most-commonly used single event indices for voltage dips are "retained voltage" and "duration". It is recommended to only use the rms voltage as a function of time, or the magnitude of the characteristic voltage for three-phase measurements, to calculate the duration. Using the characteristic voltage magnitude versus time, the retained voltage and duration can be obtained as follows.

The basic measurement of a voltage dip and swell is $U_{\text {RMS }}(1 / 2)$ on each measurement channel. Where $U_{\text {RMS }}(1 / 2)$ is defined as the value of the RMS voltage measured over one cycle and refreshed each half cycle (Polycarpou et al., 2004).

\subsubsection{For single-phase measurements}

A voltage sag begins when the $U_{\text {RMS }}(1 / 2)$ voltage falls below the dip threshold, and ends when the $U_{\text {RMS }}(1 / 2)$ voltage is equal to or above the dip threshold plus the hysterisis voltage(Polycarpou, A. et al., 2004). The retained voltage is the smallest $U_{R M S}(1 / 2)$ value measured during the dip.

The duration of a voltage dip is the time difference between the beginning and the end. Voltage sags may not be rectangular. Thus, for a given voltage sag, the duration is dependent on a predefined threshold sag value.

The user can define the sag threshold value either as a percentage of the nominal, rated voltage, or as a percentage of pre-event voltage. For measurements close to equipment terminals and at distribution voltage levels, it is recommended to use the nominal value (Bollen, 2001). At transmission voltages, the pre-event voltage may be used as a reference.

The choice of threshold obviously affects the retained voltage in per cent or per unit. The choice of threshold may also affect the measurement of the duration for voltage dips with a slow recovery. These events occur due to motor starting, transformer energizing, post-fault motor recovery, and post-fault transformer saturation.

\subsubsection{For multi-channel three phase measurement}

The voltage sag starts when the RMS voltage $U_{\text {RMS }}(1 / 2)$, drops below the threshold in at least one of the channels, and ends when the RMS voltage recovers above the threshold in all channels. The retained voltage for a multi-channel measurement is the lowest RMS voltage in any of the channels.

Several methods have been investigated leading to a single index for each event. Although this leads to higher loss of information, it simplifies the comparison of events, sites and systems. The general drawback of any single-index method is that the result no longer directly relates to equipment behaviour. Single indices are briefly described below.

Loss of Voltage:

The loss of voltage "LV" is defined as the integral of the voltage drop during the event.

$$
L_{V}=\int\{1-v(t)\} d t
$$

Loss of Energy:

The loss of energy "LE" is defined as the integral of the drop in energy during the event: 


$$
L_{E}=\int\left\{1-v(t)^{2}\right\} d t
$$

Method proposed by R. S. Thalam, 2000, defines the energy of voltage sag as:

$$
E_{V s}=\left(1-V_{p u}\right)^{2} \times t
$$

Where $t$ is the sag duration.

Method proposed by Thallam \& Heydt, 2000: The concept of "lost energy in a sag event" is introduced, in such a way that the lost energy for events on the Computer Business Equipment Manufacturers Association (CBEMA) curve is constant for three-phase measurements. The lost energy is added for the three phases:

$$
W_{a}=\left\{1-\frac{V_{a}}{V_{a} \text { nominal }}\right\}^{3.14} \times t
$$

To include non-rectangular events an integral expression may again be used. The event severity index ' $\mathrm{S}_{\mathrm{e}}$ ' is calculated from the event magnitude (in pu) and the event duration. Also essential for the method is the definition of a reference Curve.

$$
S_{e}=\frac{1-V}{1-V_{r e f}(d)}
$$

Where $V_{r e f}(d)$ is the event magnitude value of the reference curve for the same event duration. This method is illustrated by the use of the CBEMA and Information Technology Industry Council (ITIC) curves as reference curves. However the method is equally applicable with other curves.

\subsection{Site indices}

Usually the site indices have as inputs the retained voltage and duration of all sags recorded at a site over a given period. Available RMS Variation Indices for Single Sites are described below.

\subsubsection{SAFRI related index and curves}

The SAFRI index (System Average RMS Variation Frequency Index) relates how often the magnitude of a voltage sag is below a specified threshold. It is a power quality index which provides a rate of incidents, in this case voltage sags, for a system (Sabin, 2000).

SARFI-X corresponds to a count or rate of voltage sags, swell and interruptions below a voltage threshold. It is used to assess short duration rms variation events only.

SARFI-Curve corresponds to a rate of voltage sags below an equipment compatibility curve. For example SARFI-CBEMA considers voltage sags and interruptions that are not within the compatible region of the CBEMA curve.

Since curves like CBEMA do not limit the duration of a RMS variation event to 60 seconds, the SARFI-CBEMA curve is valid for events with a duration greater than $1 / 2$ cycle. To demonstrate the use of this method the following table is assumed for a given site (Polycarpou et al., 2004). 


\begin{tabular}{|c|c|c|}
\hline Event Number & Magnitude (pu) & Duration (s) \\
\cline { 2 - 3 } 1 & 0.694 & 0.25 \\
\cline { 2 - 3 } 3 & 0.459 & 0.1 \\
\cline { 2 - 3 } 4 & 0.772 & 0.033 \\
\cline { 2 - 3 } 5 & 0.47 & 0.133 \\
\hline 6 & 0.545 & 0.483 \\
\cline { 2 - 3 } 7 & 0.831 & 0.067 \\
\cline { 2 - 3 } & 0.828 & 0.05 \\
\hline 9 & 0.891 & 0.067 \\
\cline { 2 - 3 } 10 & 0.008 & 0.067 \\
\cline { 2 - 3 } 11 & 0.721 & 0.067 \\
\cline { 2 - 3 } 12 & 0.684 & 0.033 \\
\cline { 2 - 3 } & 0.763 & 0.033 \\
\hline
\end{tabular}

Table 1. Voltage sag event characteristics

The values of the table above are used with various types of scatter plot to illustrate the use of known curves in equipment compatibility studies.

\section{a. CBEMA curve Scatter Plot}

The CBEMA chart presents a scatter plot of the voltage magnitude and event duration for each RMS variation. The CBEMA group created the chart as a means to predict equipment mis-operation due to rms variations. An RMS variation event with a magnitude and duration that lies within the upper and lower limit of the CBEMA curve, has a high probability to cause mis-operation of the equipment connected to the monitored source. Observing Figure 1, the number of events which are below the lower limit of the CBEMA curve is seven, giving a SAFRI-CBEMA of seven events.

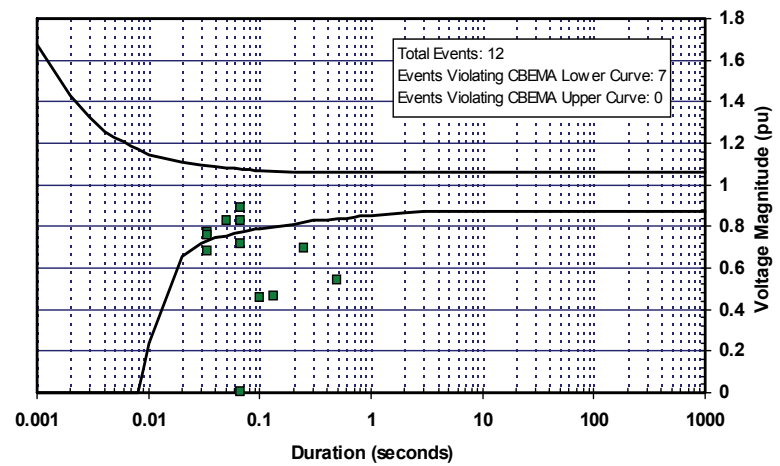

Fig. 1. The CBEMA curve scatter plot 


\section{b. ITIC Curve Scatter Plot}

The ITIC Curve describes an AC input voltage boundary that typically can be tolerated (Sabin, 2000). Events above the upper curve or below the lower curve are presumed to cause the mis-operation of information technology equipment. The curve is not intended to serve as a design specification for products or ac distribution systems. In this case, the number of events, which are below the lower limit of the ITIC curve, in Figure 2, is six, giving a SAFRIITIC of six events.

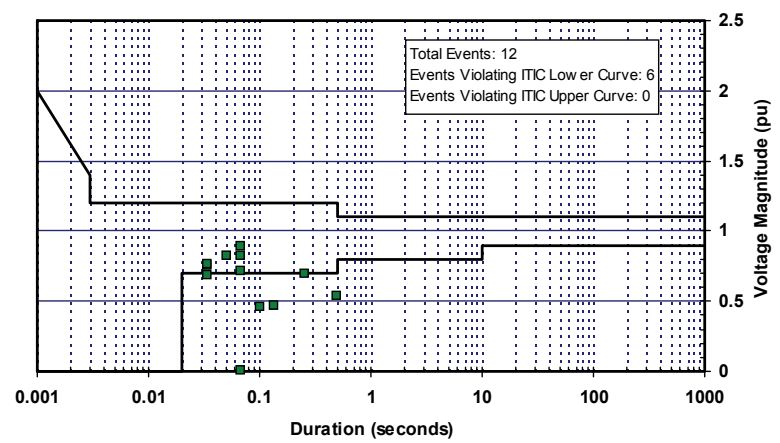

Fig. 2. The ITIC curve scatter plot

\section{c. SEMI Curve Scatter Plot}

In 1998, the Semiconductor Equipment and Materials International (SEMI) group, power quality and Equipment Ride Through Task force, recommended the SEMI Standard F-47 Curve to predict voltage sag problems for semiconductor manufacturing equipment. Figure 3 shows the application of the data of Table 1on the SEMI curve.

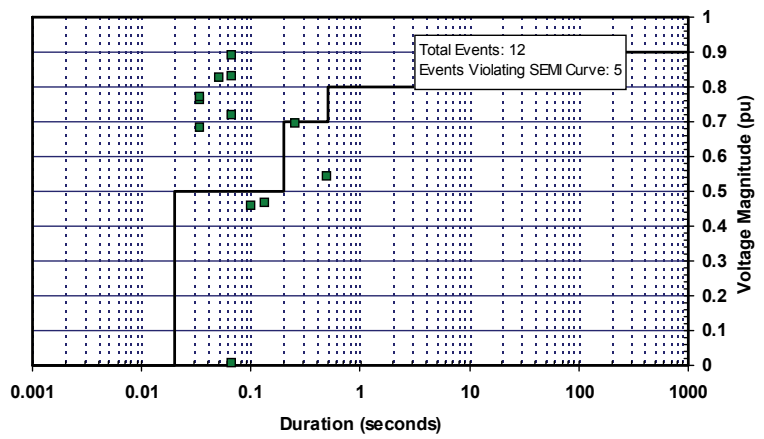

Fig. 3. SEMI Curve scatter plot

The results obtained from each combination of curves can be presented with the use of tables, such as UNIDEPE DISDIP or ESKOM Voltage sag Table, (Sabin, 2000).

\section{d. Voltage sag co-ordination chart-IEEEStd.493 and 1346}

The chart contains the supply performance for a given site through a given period, and the tolerance of one or more devices. It illustrates the number of events as a function of event 
severity. Observing the graph shown in Figure 4, there are 5 events per year where the voltage drops below $40 \%$ of nominal Voltage for $0.1 \mathrm{~s}$ or longer. Equally there are 5 events per year where the voltage drops below $70 \%$ magnitude and $250 \mathrm{~ms}$ duration.

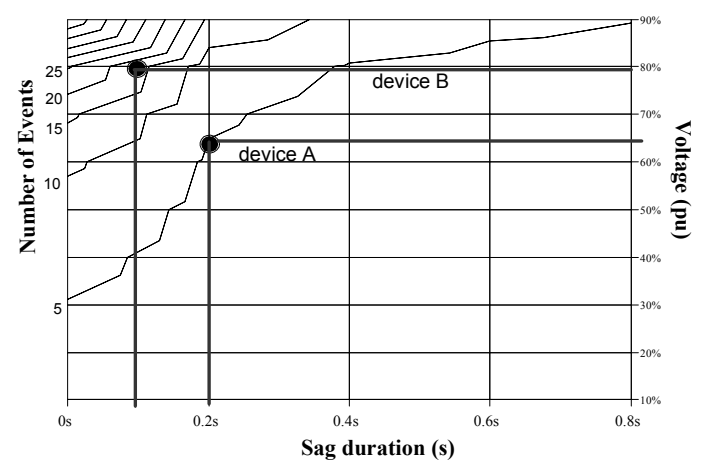

Fig. 4. Voltage sag co-ordination chart

The advantage of this method is that equipment behavior can be directly compared with system performance, for a wide range of equipment. The disadvantage of the method is that a two-dimensional function is needed to describe the site. For comparison of different sites a smaller number of indices would be preferred.

\subsubsection{Calculation methods}

\section{a. Method used by Detroit Edison}

The method calculates a "sag score" from the voltage magnitudes in the three phases (Sabin, 2000).

$$
S=1-\frac{V_{a}+V_{b}+V_{c}}{3}
$$

This sag score is equal to the average voltage drop in the three phases. The larger the sag score, the more severe the event is considered to be.

\section{b. Method proposed by Thallam}

A number of site indices can be calculated from the "voltage sag energy" (Thallam, 2000). The "Voltage Sag Energy Index" (VSEI) is the sum of the voltage sag energies for all events measured at a given site during a given period:

$$
V S E I=\sum_{i} \mathrm{E}_{V S_{-} i}
$$

The "Average Voltage Sag Energy Index" (AVSEI) is the average of the voltage sag energies for all events measured at a given site during a given period:

$$
A V S E I=\frac{1}{N} \sum_{i=1}^{N} \mathrm{E}_{V S_{-} i}
$$


A sensitive setting will result in a large number of shallow events (with a low voltage sag energy) and this in a lower value for AVSEI.

The sag event frequency index at a particular location and period is suggested as the number of qualified sag events at a location and period (Thallam \& Koellner, 2003).

The System sag count index is the total number of qualified voltage sag events over the number of monitor locations. By the expression qualifying events, it implies a voltage less than $90 \%$, with event duration limited to 15 cycles and energy greater or equal to 100 .

\subsubsection{Non-rectangular events}

Non-rectangular events are events in which the voltage magnitude varies significantly during the event. A method to include non-rectangular events in the voltage-sag coordination chart is also applicable according to the IEEE defined standard (IEEE Std.493, 1997). Alternatively, the function value can be defined as the number of times per year that the RMS voltage is less than the given magnitude for longer than the given duration.

EPRI-Electrotek mentions that each phase of each ms variation measurement may contain multiple components (Thallam, 2000). Consequently, these phase rectangular voltage sag measurements are easily characterized with respect to magnitude and duration. Approximately $10 \%$ of the events are non-rectangular. These events are much more difficult to characterize because no single magnitude-duration pair completely represent the phase measurement.

The method suggested for calculating the indices used by EPRI-Electrotek is called the "Specified Voltage" method. This method designates the duration as the period of time that the rms voltage exceeds a specified threshold voltage level used to characterize the disturbance.' The consequence of this method is that an event may have a different duration when being assessed at different voltage thresholds as shown in Figure 5.

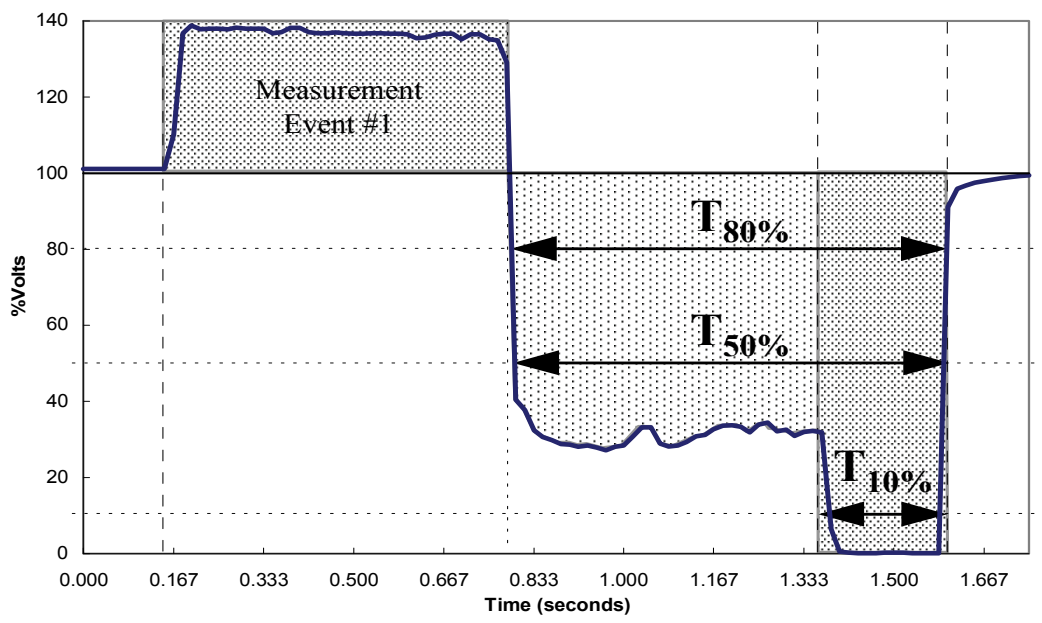

Fig. 5. Illustration of "specified voltage" characterization

Most of the single site indices relate the magnitude and duration of the sag and the number of events. These events can be grouped in order to make their counting easier and more 
practical. Power quality surveys in the past have just referred to the number of voltage sags per year for a given site. This value could include minor events, which do not affect any equipment.

The Canadian Electrical Association recommends tracking 4 indices for sag magnitudes (referring to the remaining voltage), of $85 \%, 70 \%, 40 \%$ and $1 \%$. The latter refers to interruptions rather than sags.

ESKOM (South African Utility), groups voltage sags into five classes (Sabin, 2000):

class Y: $80 \%$ - 90\% magnitude, $20 \mathrm{~ms}-3$ sec duration

class X: $40 \%$ - 80\% magnitude, $20 \mathrm{~ms}$ - $150 \mathrm{~ms}$ duration

class S: $40 \%$ - 80\% magnitude, $150 \mathrm{~ms}-600 \mathrm{~ms}$ duration

class T: 0 - 40\% magnitude, $20 \mathrm{~ms}-600 \mathrm{~ms}$ duration

class Z: 0 - 80\% magnitude, $600 \mathrm{~ms}-3$ sec duration

EPR1 -Electrotek suggests the following five magnitudes and three duration ranges to characterize voltage thresholds:

a. RMS variation Frequency for voltage threshold $X$ : with $X=90 \%, 80 \%, 70 \%, 50 \%, 10 \%$ : the number of events per year with magnitude below $X$, and duration between 0.5 cycle and $60 \mathrm{sec}$.

b. Instantaneous RMS variation Frequency for voltage threshold $X$ : with $X=90 \%, 80 \%$, $70 \%, 50 \%$ : the number of events per year with magnitude below $X$, and duration between 0.5 cycle and $0.5 \mathrm{sec}$.

c. Momentary RMS variation Frequency for voltage threshold $X$ : with $X=90 \%, 80 \%, 70 \%$, $50 \%$ : the number of events per year with magnitude below $X$, and duration between 0.5 sec and 3 sec.

d. Momentary RMS variation Frequency for voltage threshold I0\%: the number of events per year with a magnitude below $10 \%$, and a duration between 0.5 cycle and 3 sec.

e. Temporary RMS variation Frequency for voltage threshold $X$ : with $X=90 \%, 8070,70 \%$, $50 \%, \mathrm{I} 0 \%$ : the number of events per year with magnitude below $X$, and duration between $3 \mathrm{sec}$. and $60 \mathrm{sec}$.

The duration ranges are based on the definition of instantaneous, momentary and temporary, as specified by IEEE (IEEE Std. 1159, 1995).

\subsection{System indices}

System Indices are typically a weighted average of the single-site indices obtained for all or a number of sites within the system. The difficulty lies in the determination of the weighting factors. In order to assess any indices for the system, first monitoring of the quality of supply must take place. When the Electric Power Research Institute (EPRI)-Distribution Power Quality (DPQ) program placed monitoring equipment on one hundred feeders, these feeders needed to adequately represent the range of characteristics seen on distribution systems. This required the researchers to use a controlled selection process to ensure that both common and uncommon characteristics of the national distribution systems were well represented in the study sample. Thus a level of randomness is required. Many devices are susceptible to only the magnitude of the variation. Others are susceptible to the combination of magnitude and durationOne consideration in establishing a voltage sag index is that the less expensive a measuring device is, the more likely it will be applied at many locations, more completely representing the voltage quality electricity users are experiencing. 
With this consideration in mind, sag monitoring devices are generally classified into less expensive devices that can monitor the gross limits of the voltage sag, and more expensive devices that can sample finer detail such as the voltage-time area and other features that more fully characterize the sag.

The sag limit device senses the depth, of the voltage sag. The sag area device can sample the sag in sufficient detail to plot the time profile of the sag. With this detail it could give a much more accurate picture of the total sag area, in volt-seconds, as well as the gross limits; the retained voltage, $\mathrm{V}_{\mathrm{r}}$, is also shown.

The developed RMS variation indices proposed by EPRI-Electrotek, are designed to aid in the assessment of service quality for a specified circuit area. The indices are defined such that they may be applied to systems of varying size (Bollen, 2001).Values can be calculated for various parts of the distribution system and compared to values calculated for the entire system.

Accordingly, the four indices presented assess RMS variation magnitude and the combination of magnitude and duration.

\section{a. System Average RMS (Variation) Frequency Index voltage $_{\left(S^{\prime}\right.}$ ARFI $\left._{\mathbf{x}}\right)$}

$\mathrm{SARFI}_{\mathrm{x}}$ represents the average number of specified rms variation measurement events that occurred over the assessment period per customer served, where the specified disturbances are those with a magnitude less than $x$ for sags or a magnitude greater than $x$ for swells. Notice that SARFI is defined with respect to the voltage threshold ' $x$ ' (Sabin, 2000).

$$
S A R F I_{x}=\frac{\sum N_{i}}{N_{T}}
$$

where

$x=$ percentage of nominal rms voltage threshold; possible values $-140,120,110,90,80,70$, 50 , and 10

$N_{i}=$ number of customers experiencing short-duration voltage deviations with magnitudes above $\mathrm{x} \%$ for $\mathrm{x}>100$ or below $\mathrm{x} \%$ for $\mathrm{x}<100$ due to measurement event $i$

$N_{T}=$ number of customers served from the section of the system to be assessed

\section{b. System Instantaneous Average RMS (Variation) frequency Index voltage $\left(\operatorname{SIARFI}_{\mathbf{x}}\right)$}

SIARFI $_{x}$ represents the average number of specified instantaneous rms variation measurement events that occurred over the assessment period per customer served. The specified disturbances are those with a magnitude less than $x$ for sags or a magnitude greater than $x$ for swells and duration in the range of $0.5-30$ cycles.

$$
\text { SIARFI }_{x}=\frac{\sum N I_{i}}{N_{T}}
$$

Where:

$x=$ percentage of nominal rms voltage threshold; possible values $-140,120,110,90,80,70$, and 50

$N I_{i}=$ number of customers experiencing instantaneous voltage deviations with magnitudes above $\mathrm{x} \%$ For $\mathrm{x}>100$ or below $\mathrm{x} \%$ for $\mathrm{x}<100$ due to measurement event $i$ 
Notice that $\mathrm{SIARFI}_{x}$ is not defined for a threshold value of $x=10 \%$. This is because IEEE Std. 1159,1995 , does not define an instantaneous duration category for interruptions.

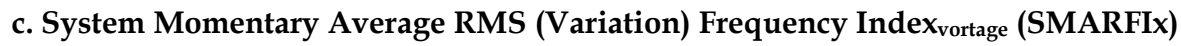

In the same way that SIARFlx is defined for instantaneous variations, SMARFlx is defined for variations having a duration in the range of 30 cycles to 3 seconds for sags and swells, and in the range of 0.5 cycles to 3 seconds for interruptions.

$$
S M A R F I_{x}=\frac{\sum N M_{i}}{N_{T}}
$$

$x=$ percentage of nominal rms voltage threshold; possible values - 140, 120, 110, 90, 80, 70, 50 , and 10

$N M=$ number of customers experiencing momentary voltage deviations with magnitudes above $\mathrm{X} \%$ for $\mathrm{X}>100$ or below $\mathrm{X} \%$ for $\mathrm{X}<100$ due to measurement event $i$.

\section{d. System Temporary Average RMS (Variation) Frequency Index vortage $_{\left(S T A R F I_{x}\right)}$}

$\mathrm{STARFI}_{\mathrm{x}}$ is defined for temporary variations, which have a duration in the range of 3 - 60 seconds.

$$
\operatorname{STARFI}_{x}=\frac{\sum N T_{i}}{N_{T}}
$$

$x=$ percentage of nominal rms voltage threshold; possible values $-140,120,110,90,80,70$, 50 , and 10.

$N T_{i}=$ number of customers experiencing temporary voltage deviations with magnitudes above $\mathrm{x} \%$ for $\mathrm{x}>100$ or below $\mathrm{x} \%$ for $\mathrm{x}<100$ due to measurement event $i$.

As power networks become more interconnected and complex to analyse, the need for power quality indices to be easily assessable, and representative of the disturbance they characterise with minimum parameters, arises. This section has presented the various Voltage sag indices available in literature. Most of these indices are characterized through the sag duration and magnitude. To demonstrate the theory of equipment compatibility, with the use of the System Average RMS Variation Frequency Index, various power acceptability curves were used.

Electricity distribution companies need to assess the quality of service provided to customers. Hence, a common index terminology for discussion and contracting is useful. Future voltage sag indices need to be adjustable and adaptable to incorporate future changes in technology and system parameters. This would enable implementation of indices into the next generation of power system planning software.

\section{Voltage sag mathematical indices}

In this section of the chapter, the mathematical formulation of two voltage sag indices ( $\xi$ and $\left.\zeta_{1,2}\right)$ is introduced as well as the results of the investigation towards their accuracy establishment. The Mathematical equations describing the development of a Combined Voltage Index (CVI) are also presented as well as the results obtained by the verification process. The index supervises the power quality of a system, through characterising voltage 
sags. The voltage sags are caused by an increase in reactive demand due to induction motor starting.

A feeder can be modeled by an equivalent two-port network, as shown in Figure 6.

The sending end voltage and current of the system can be represented by equations 13 and 14 .

$$
\begin{gathered}
U_{s} \angle \delta_{s}=A U_{r} \angle \delta_{r}+B I_{r} \\
I_{s}=C U_{r} \angle \delta_{r}+D I_{r}
\end{gathered}
$$

Where $U_{s}$ is the sending end voltage, $I_{s}$ the sending end current, $U_{r}$ the receiving end voltage, $I_{r}$ the receiving end current, $\delta_{\mathrm{s}}$ the sending end voltage angle, $\delta_{\mathrm{r}}$ the receiving end voltage angle, and $\mathrm{A}, \mathrm{B}, \mathrm{C}, \mathrm{D}$ are the two port network constants. For a short length line, corresponding to distribution network, the two port network parameters can be approximated as: $A=D=1, B=Z \angle \theta, C=0$. Where $Z$ is the transmission line impedance vector magnitude, and $\theta$ the transmission line impedance vector angle.

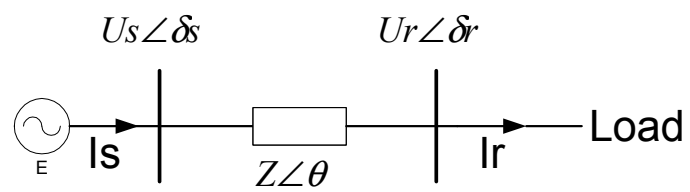

Fig. 6. The equivalent two port network model.

The line power flow, for the active power at the sending and receiving end of the line, can be described by (15) and (16).

$$
\begin{aligned}
& P_{s}=\frac{U_{s}^{2}}{Z} \operatorname{Cos}(\theta)-\frac{U_{s} U_{r}}{Z} \operatorname{Cos}\left(\theta+\delta_{s}-\delta_{r}\right) \\
& P_{r}=\frac{U s U r}{Z} \operatorname{Cos}(\theta+\delta r-\delta s)-\frac{U r^{2}}{Z} \operatorname{Cos}(\theta)
\end{aligned}
$$

\section{1 ' $\zeta$ ' index}

If the index $\zeta$ signifies the voltage magnitude during the sag as a per unit function of the sending voltage $\left(\mathrm{U}_{\mathrm{r}}=\zeta \mathrm{U}_{\mathrm{s}}\right)$, and is substituted in equation 16, equation 17 yields (Polycarpou \& Nouri, 2005).

$$
\frac{\zeta U_{s}^{2}}{Z} \operatorname{Cos}\left(\theta+\delta_{r}-\delta_{s}\right)-\frac{\left(U_{s} \zeta\right)^{2}}{Z} \operatorname{Cos}(\theta)-P_{r}=0
$$

Thus the solution of the second order equation, resulting from (17), can be calculated using equation (18).

$$
\zeta_{1,2}=\frac{\operatorname{Cos}\left(\theta+\delta_{r}-\delta_{s}\right) \pm\left(\operatorname{Cos}^{2}\left(\theta+\delta_{r}-\delta_{s}\right)-\frac{4 Z P_{r} \operatorname{Cos} \theta}{U_{s}^{2}}\right)^{\frac{1}{2}}}{2 \operatorname{Cos} \theta}
$$


Equation 18 provides a tool to calculate the voltage sag , as a per unit value of the sending end voltage, through angles and power demand.

However, since the equation is obtained through a quadratic equation, it has two solutions. $\zeta_{1}$ will be valid for a specific range of parameters. In the same way $\zeta_{2}$ will be valid for a different range of parameters. The validity of the two solutions, $\zeta_{1}$ and $\zeta_{2}$, with the use of various line $X / R$ ratios is investigated in (Nouri et al., 2006). $X / R$ ratio varies from Distribution to Transmission according to the cables used for the corresponding voltages. Typical values of $\mathrm{X} / \mathrm{R}$ ratio are: for a $33 \mathrm{kV}$ overhead line -1.4 , for a $132 \mathrm{kV}$ overhead line -2.4 , for a $275 \mathrm{kV}$ overhead line -8.5 , for a $400 \mathrm{kV}$ overhead line -15 . A distribution line example is the IEEE34, $24.9 \mathrm{kV}$ overhead line with $\mathrm{X} / \mathrm{R}$ ratio of 0.441 .

According to the parameters either $\zeta_{1}$ or $\zeta_{2}$ will be the correct answer which should match the receiving end voltage.

The point of intersection of $U_{\mathrm{r}}$ with $\zeta_{1}$ and $\zeta_{2}$, occurs when $\left(\zeta_{1}-\zeta_{2}\right) \cos \theta$ is equal to zero, when both solutions are identical. However, in practice a gap develops when both solutions approach the Ur axis, where none of the two solutions accurately represent the receiving voltage Ur, as seen in Figure 7.

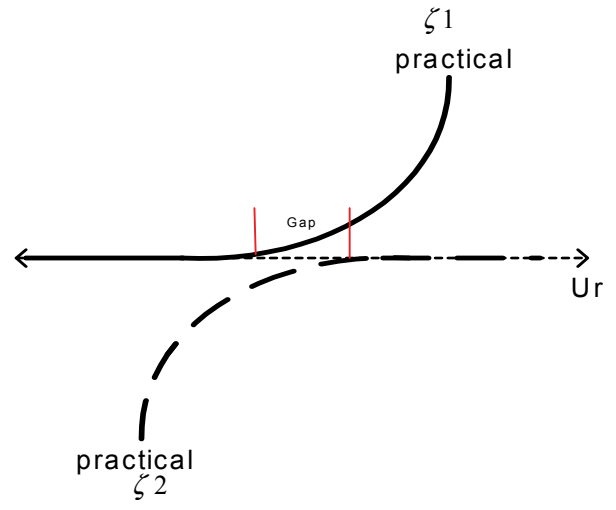

Fig. 7. Developed gap of inaccuracy

The distance between the two curves at the point of the gap can be defined by equation 19 .

$$
\zeta_{1}-\zeta_{2}=\frac{\left(\cos ^{2}\left(\theta+\delta_{r}-\delta_{s}\right)-\frac{4 Z P_{r} \cos \theta}{U_{s}{ }^{2}}\right)^{\frac{1}{2}}}{\operatorname{Cos} \theta}
$$

In order to fully investigate the range of accuracy of the two solutions, $\mathrm{X} / \mathrm{R}$ ratio values of 1 to 15 are used for the line impedance. Since the receiving end power varies according to the load, five loading conditions are used in the investigation. Each loading consists of induction motors. The loads are switched in the system one by one to create the effect of supplying minimum load (one motor) and maximum load (five motors).

Using MathCad, the value of $\left(\zeta_{1}-\zeta_{2}\right) \cos \theta$ is calculated for five different loadings and each $X / R$ ratio, starting from one up to fifteen in steps of one. The results can be seen in Figure 8 (Nouri et al., 2006). 


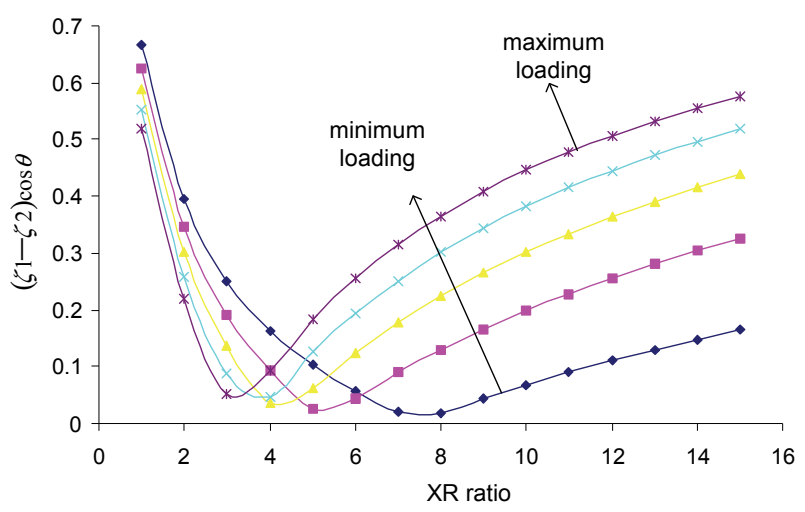

Fig. 8. Mathematical results obtained for $\left(\zeta_{1}-\zeta_{2}\right) \cos \theta$

It can be observed from Figure 8 , that the minimum values of $\left(\zeta_{1}-\zeta_{2}\right) \cos \theta$ occur within $\mathrm{X} / \mathrm{R}$ ratio values of 3 to 8 , for all test cases. Therefore during those points, the gap of inaccuracy for the index can be expected for the two solutions. Taking under consideration Figure 7, solution $\zeta_{1}$ should cover the ranges less than three and solution $\zeta_{2}$ should cover $X / R$ greater than eight. Between those $X / R$ values the gap position varies according to the loading and the $X / R$ ratio of the line, thus it cannot be generalized. The accuracy of the defined location of the gap is and verified through application on a two-bus system within Power system Computer Aided Design software. The resulting data for a test system of $X / R$ ratio equal to five, shown in Figure 9, verifies the mathematical theory concerning the gap.

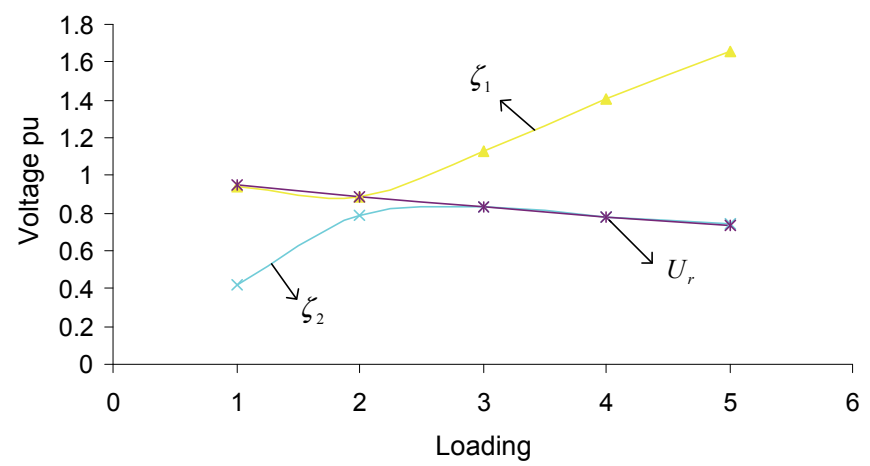

Fig. 9. $\zeta_{1}, \zeta_{2}$ and $U_{\mathrm{r}}$ for line $X / R$ ratio of five

As shown in Figure 9, the plot of $\zeta_{1}$ has a negative slope until loading two, and then it becomes positive. Whereas the plot of $\zeta_{2}$ has a positive slope for the initial loadings and becomes negative when the third load is switched in.

Throughout the investigation of various $X / R$ ratios a pattern was established regarding the slope of $\zeta_{1}$ and $\zeta_{2}$. When the slope of $\zeta_{1}$ is negative it is the accurate solution. When $\left(\zeta_{1}-\zeta_{2}\right) \cos \theta$ reaches minimum, $\zeta_{1}$ deviates and $\zeta_{2}$ becomes the correct answer with 
negative slope. Thus their slope is directly related to the minimum value of $\left(\zeta_{1}-\zeta_{2}\right) \cos \theta$ and to the accuracy of each solution. The relationship between the slope of $\zeta_{1}$ and $\zeta_{2}$ with the index accuracy and choice of solution is described by equation 20 . The value of ' $i$ ' is 1 for $\zeta_{1}$ or 2 for $\zeta_{2}$.

$$
\forall \frac{\partial\left(\zeta_{i}\right)}{d \text { Loading }}<0 \Rightarrow \zeta i=\text { valid }
$$

\subsection{Combined voltage index}

If $\xi$ signifies the voltage magnitude during the sag as a per unit function of the sending voltage $\left(\mathrm{U}_{\mathrm{r}}=\xi \mathrm{U}_{\mathrm{s}}\right)$, and is substituted in equation 15, equation 21 yields.

$$
\xi=\frac{\cos \theta-\frac{Z P_{s}}{U_{s}^{2}}}{\operatorname{Cos}\left(\theta+\delta_{s}-\delta_{r}\right)}
$$

$\xi$ and $\zeta_{1,2}$ signify the voltage magnitude during the sag as a per unit function of the sending voltage. When the two equations are combined, the resulting Combined Voltage Index (CVI), described by equation 22 features improved accuracy (Polycarpou \& Nouri,2005). The value of CVI is the value of the receiving end voltage of the system power line.

$$
\frac{a \xi+\zeta}{a+1}=C V I
$$

Where ' $a$ ' is the value of the scaling factor (Polycarpou \& Nouri, 2009) and is defined as shown in equation 23.

$$
a=\frac{1}{n} \sum_{l=1}^{n}\left[\frac{1+\sqrt{1-h l}-\left[w l+\sqrt{w l^{2}-h l}\right]}{2 k l}\right]
$$

Where:

$$
\begin{aligned}
& w=\cos \left(\theta+\delta_{r}-\delta_{s}\right) \\
& j=\cos \left(\theta+\delta_{s}-\delta_{r}\right) \\
& k=\cos \theta \\
& h=\frac{4 Z P_{r} K}{U_{s}^{2}}
\end{aligned}
$$

and $\mathrm{n}=$ Number of loads supplied.

For simplicity, the value of scaling factor setting is 1.6 for the entire range of line $\mathrm{X} / \mathrm{R}$ ratios investigated in the next sections of the chapter. Equations 18, 21 and 22 provide a tool to calculate the load voltage, as a per unit value of the sending end voltage. The equations are functions of receiving end variables such as the the receiving end voltage angle, $\delta_{\mathrm{r}}$, and the receiving end power $P_{r}$. The receiving end power can be described by $P_{r}=P_{s}-I^{2} Z \cos \theta$. The angle $\delta_{\mathrm{r}}$ of the receiving end voltage can be represented by sending end quantities through equation 24 (Nouri \& Polycarpou, 2005). 


$$
\delta_{r}=a \tan \left[\frac{U_{s} \sin \left(\delta_{s}\right)-Z I \sin (\theta+i)}{U_{s} \cos \left(\delta_{s}\right)-Z I \cos (\theta+i)}\right]
$$

Assuming the presence of an infinite bus at the sending end, equation 24 can be reduced to equation 25 .

$$
\delta_{r}=a \tan \left[\frac{Z I \sin (\theta+i)}{Z I \cos (\theta+i)-1}\right]
$$

\subsubsection{Combined voltage index accuracy investigation}

Most distribution power system loads have a power factor of 0.9 to 1 . Industrial companies have to keep their power factor within limits defined by the regulatory authorities, or apply power factor correction techniques, or suffer financial penalties. In order to cover a wider area of investigation it is decided to simulate loads of power factor 0.8 to 0.99 .

The relationship between the power factor and the $\mathrm{X} / \mathrm{R}$ ratio of a load is: $\mathrm{X} / \mathrm{R}$ ratio $=\tan \theta$, where $\theta=\cos ^{-1} p f$.

In order to achieve the load $X / R$ ratio variation the circuit model of the double cage induction motor, used within the PSCAD environment, is considered. The Sqc100 Motor circuit diagram is shown in Figure 10 (Polycarpou \&Nouri, 2002).

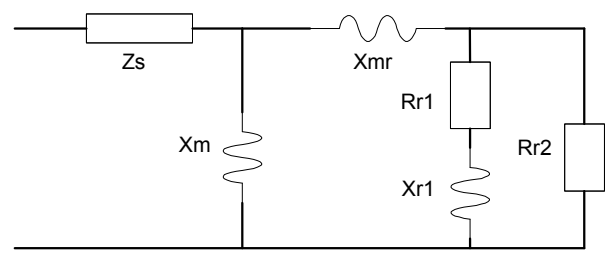

Fig. 10. The Double cage Induction motor model circuit diagram

The motor circuit parameters are:

Slip: 0.02, Stator resistance(Rs) $2.079 \mathrm{pu}$, First cage resistance(Rr1) $0.009 \mathrm{pu}$, Second cage resistance $(\mathrm{Rr} 2) 0.012 \mathrm{pu}$, Stator reactance $(\mathrm{Xs}) 0.009 \mathrm{pu}$, Magnetizing reactance $(\mathrm{Xm}) 3.86 \mathrm{pu}$ Rotor mutual reactance $(\mathrm{Xmr}) 0.19 \mathrm{pu}$, First cage reactance $(\mathrm{Xr1}) 0.09 \mathrm{pu}$

The resistance of the stator winding is varied in order to achieve the required power factor and $X / R$ ratio. Load $X / R$ ratios of 0.1 to 0.75 are investigated. Two distribution line $X / R$ ratios are used in the investigation in order to observe the accuracy of the index while varying both load as well as line $X / R$ ratio for distribution system lines. The line $X / R$ ratios are 0.12087 , and 1 . The amount of loading is varied through introducing five identical motors for each investigated case. The results of this investigation are presented in the following subsections.

\section{a. Distribution Line $X / R$ ratio is $\mathbf{0 . 1 2 0 8 1 7}$}

The per unit receiving voltage, obtained with variation of the load $X / R$ ratio while line $X / R$ ratio is 0.120817 , can be seen in Figure $11 . \mathrm{M}_{1}$ Signifies the minimum loading with the first motor being switched in. As any switched in motor reaches rated speed, the next load is switched in the system. $\mathrm{M}_{5}$ corresponds to the Maximum loading with the fifth motor being 
switched in while the previous four are in steady state operation. The Combined Voltage Index (CVI) deviation corresponding to this scenario can be seen in Figure 12.

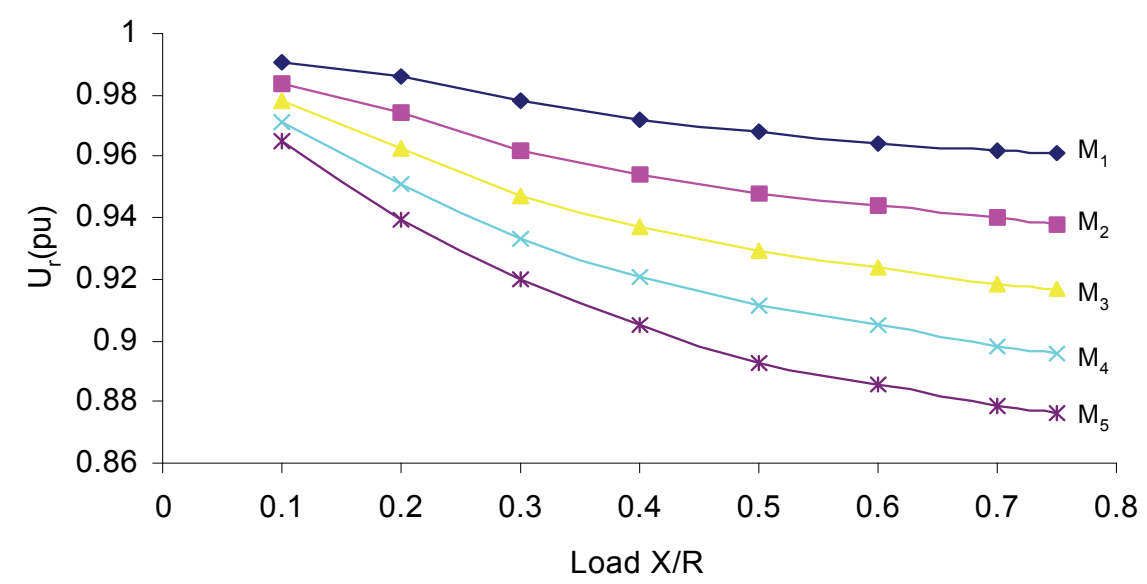

Fig. 11. $\mathrm{U}_{\mathrm{r}}$ for various Load $\mathrm{X} / \mathrm{R}$ ratios and loadings whilst Line $\mathrm{X} / \mathrm{R}$ is 0.120817

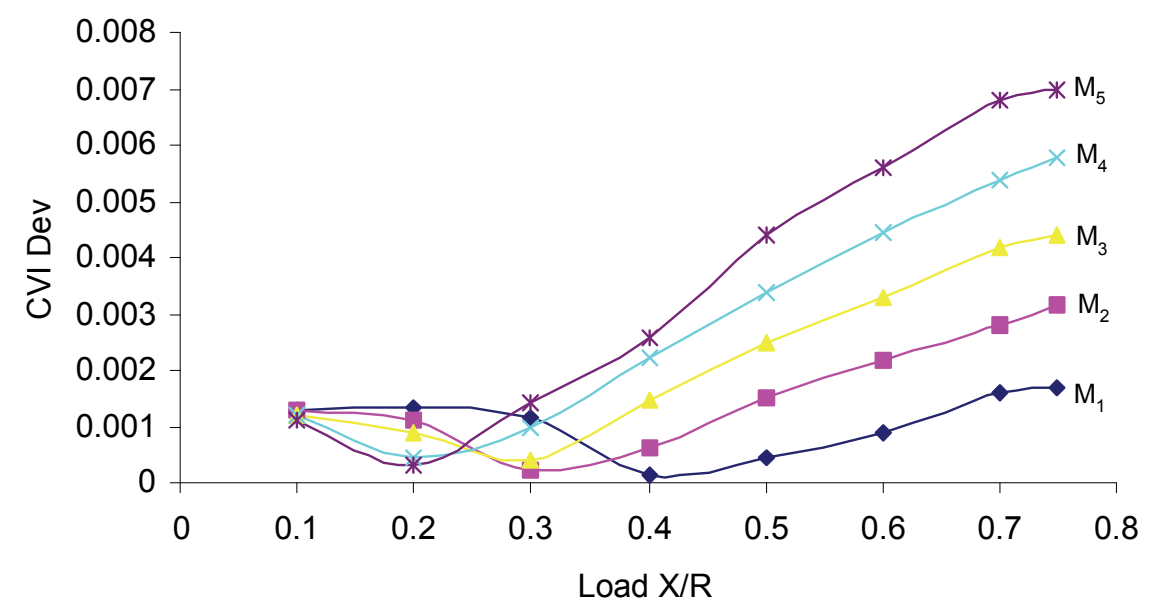

Fig. 12. CVI deviation for load $X / R$ variation whilst line $X / R=0.120817$

Observing the figures above it can be concluded that as loading levels $\left(M_{1}\right.$ to $\left.M_{5}\right)$ and $X / R$ ratio increases, the receiving end voltage naturally decreases. This is due to the voltage drop occurring on the impedance of the transmission line. The accuracy of the proposed index is well within acceptable limits $(0.7 \%$ in the worst case). Thus for line $X / R$ ratio of 0.120817 the index is capable of calculating the receiving end voltage for variation of load $X / R$ ratio.

\section{b. Distribution Line $X / R$ ratio is 1}

The resulting receiving end voltage, obtained through variation of the load $X / R$ ratio for the specific line $\mathrm{X} / \mathrm{R}$ ratio can be seen in Figure 13. 


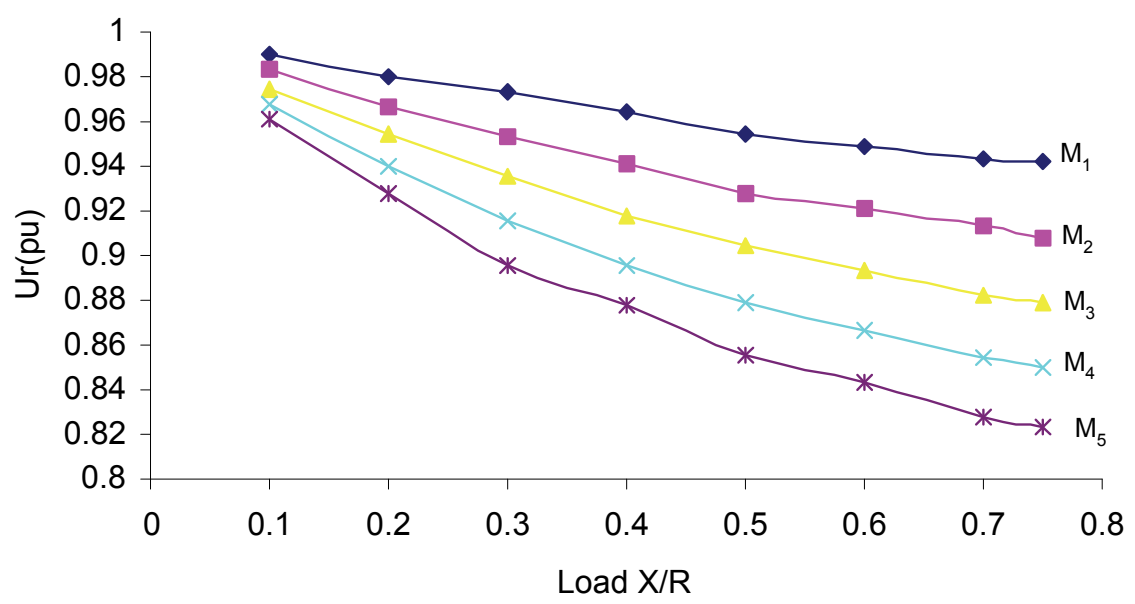

Fig. 13. $U_{r}$ for load $X / R$ variation whilst line $X / R=1$

Comparing Figure 11 to Figure 13, it is concluded that as the $X / R$ ratio of the line increases, any load increment has more severe impact on the receiving end voltage due to the impedance magnitude of the line. The CVI deviation corresponding to this investigation case can be seen in Figure 14.

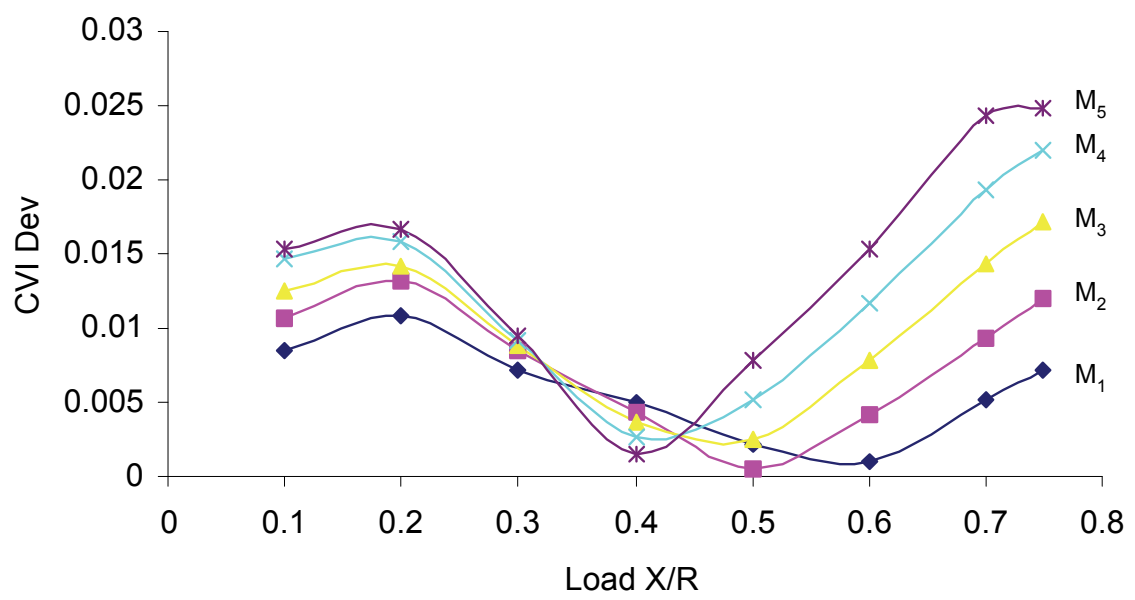

Fig. 14. CVI deviation for load $X / R$ variation whilst line $X / R=1$

As the $X / R$ ratio of the line increases the index accuracy did not decrease homogeneously. Between the values of 0.3 and 0.5 for load $X / R$ an area of decreased inaccuracy can be observed. This is due to the scaling factor setting being 1.6 for the entire range of line $X / R$ ratios investigated. The accuracy of the index is within acceptable margins as the largest deviation is within 2.5\% (Polycarpou \& Nouri, 2009). The index is within acceptable accuracy limits. 


\section{Conclusion}

The first part of this chapter presents various statistical voltage sag indices proposed by electrical association organisations and indices suggested by recent researchers. These indices are used to characterise any voltage sag, according to the individual index point of view. The procedure to evaluate the quality of supply, reference to non-rectangular events and equipment compatibility issues are also presented. To demonstrate the theory of equipment compatibility, with the use of System Average RMS Variation Frequency Index, various power acceptability curves were used.

Furthermore the formulation defining a set of Mathematical voltage sag indices, leading to the Combined Voltage Index, is presented. Various motor power factors and loading levels are used in order to establish the behavior of the index for a wide range of loads. Mathematical description of voltage angle characteristics, relating to line $X / R$ ratio variation is also illustrated. A relationship is established between the slope of $\zeta$ and the range of accuracy for each solution of the quadratic index. The CVI has proven to be easy to assess, accurate and representative of the disturbance it characterizes at distribution level. If better accuracy is required for distribution system applications, the scaling factor can be varied to achieve it. The described CVI index can be used in conjunction with optimization techniques for power quality improvement as well as power system operation optimization. The index is adaptable to incorporate future changes in technology and system parameters. This enables its implementation into the next generation of power system planning software.

\section{Acknowledgment}

The author would like to express his appreciation to the University of the West of England, UK, and to Prof. Hassan Nouri, for the opportunity to carry out significant portion of the research work presented in this chapter at their establishments, as a member of the Power Systems and Electronics Research Group.

\section{References}

Bergeron,R. (1998). Canadian electrical association approved quality indices. IEEE Power summer meeting

Bollen, M. (2000). Voltage sag indices-Draft 2. Working document for IEEE P1564and CIGRE WG 36-07

Bollen, M. (2001).Voltage Sags in Three-Phase Systems. IEEE Power Eng. Review, pp. 8-15.

Bollen, M.\&Styvaktakis,S. ( 2000). Characterization of three phase unbalanced sags, as easy as one, two, three. IEEE Power summer meeting.

IEEE Std. 1159 (1995). Recommended practice for monitoring electric power quality.

IEEE Std. 1250 (1995) IEEE Guide for Service to Equipment Sensitive to Momentary Voltage Disturbances -Description, Corrected Edition Second Printing

IEEE Std. 493 (1997). Gold book, IEEE recommended practice for the design of reliable industrial and commercial power systems

IEEE Std. 1100, (1999). IEEE Recommended Practice for Powering and Grounding Electronic Equipment 
Nouri, H., \& Polycarpou, A. (2005). Load Angle Characteristic Analysis For A Radial System Using Various Line X/R Ratios During Motor Load Increment, Paper presented at the Universities Power Engineering Conference, Cork, Ireland

Nouri H, Polycarpou A. and Li z.(2006). Mathematical Development, Investigation and Simulation of a New Quadratic Voltage Index, IEEE 41st Int. Universities Power Engineering Conference, Newcastle-Upon-Tyne, UK, pp 1-6

Polycarpou, A., \&Nouri,H. (2002). Analysis and Simulation of Bus Loading Conditions on Voltage Sag in an Interconnected Network, Paper presented at the Universities Power Engineering Conference, Staffordshire, UK

Polycarpou, A., Nouri,H., Davies,T., \&Ciric, R. (2004). An Overview Of Voltage Sag Theory, Effects and Equipment Compatibility, Paper presented at the Universities Power Engineering Conference, Bristol, UK

Polycarpou, A., \&Nouri,H. (2005). A New Index for On Line Critical Voltage Calculation of Heavily Loaded Feeders, Paper presented at the Power Tech Conference, St. Petersburg, Russia

Polycarpou A. and Nouri H.(2009). Investigation into the accuracy limits of a proposed Voltage Sag Index, IEEE 44th Int. Universities Power Engineering Conference, Glasgow, Scotland, UK, pp 1-5

Sabin, D. (2000). Indices used to assess RMS Voltage variations. IEEE P1564. summer meeting. Thallam, R. (2000). Comments on voltage sag indices. IEEE P1564 internal document.

Thallam, R.\&Heydt, G. T.(2000). Power acceptability and voltage sag indices in the three phase sense. IEEE Power summer meeting

Thallam, R. \& Koellner, K.(2003). SRP Voltage sag index methodology-Experience and FAQs. IEEE PES Meeting 


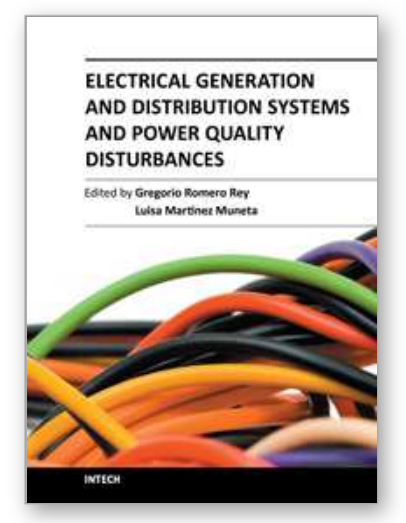

\section{Electrical Generation and Distribution Systems and Power Quality Disturbances}

Edited by Prof. Gregorio Romero

ISBN 978-953-307-329-3

Hard cover, 304 pages

Publisher InTech

Published online 21, November, 2011

Published in print edition November, 2011

The utilization of renewable energy sources such as wind energy, or solar energy, among others, is currently of greater interest. Nevertheless, since their availability is arbitrary and unstable this can lead to frequency variation, to grid instability and to a total or partial loss of load power supply, being not appropriate sources to be directly connected to the main utility grid. Additionally, the presence of a static converter as output interface of the generating plants introduces voltage and current harmonics into the electrical system that negatively affect system power quality. By integrating distributed power generation systems closed to the loads in the electric grid, we can eliminate the need to transfer energy over long distances through the electric grid. In this book the reader will be introduced to different power generation and distribution systems with an analysis of some types of existing disturbances and a study of different industrial applications such as battery charges.

\section{How to reference}

In order to correctly reference this scholarly work, feel free to copy and paste the following:

Alexis Polycarpou (2011). Power Quality and Voltage Sag Indices in Electrical Power Systems, Electrical Generation and Distribution Systems and Power Quality Disturbances, Prof. Gregorio Romero (Ed.), ISBN: 978-953-307-329-3, InTech, Available from: http://www.intechopen.com/books/electrical-generation-anddistribution-systems-and-power-quality-disturbances/power-quality-and-voltage-sag-indices-in-electricalpower-systems

\section{INTECH}

open science | open minds

\section{InTech Europe}

University Campus STeP Ri

Slavka Krautzeka 83/A

51000 Rijeka, Croatia

Phone: +385 (51) 770447

Fax: +385 (51) 686166

www.intechopen.com

\section{InTech China}

Unit 405, Office Block, Hotel Equatorial Shanghai

No.65, Yan An Road (West), Shanghai, 200040, China

中国上海市延安西路65号上海国际贵都大饭店办公楼 405 单元

Phone: +86-21-62489820

Fax: $+86-21-62489821$ 
(C) 2011 The Author(s). Licensee IntechOpen. This is an open access article distributed under the terms of the Creative Commons Attribution 3.0 License, which permits unrestricted use, distribution, and reproduction in any medium, provided the original work is properly cited. 